\title{
Clinical evaluation of periodontal health during orthodontic treatment with fixed appliances
}

\author{
Hănțoiu T*, Monea Adriana, Lazăr Luminița, Hănțoiu Liana \\ University of Medicine and Pharmacy of Tirgu Mures, Romania
}

\begin{abstract}
Objectives: Fixed orthodontic appliances make daily application of oral hygiene standard procedures more difficult and in time may lead to accumulation of oral biofilms and development of gingivitis and hyperplasia. The aim of the study is to evaluate the periodontal health expressed by clinical indices in patients under orthodontic treatment with fixed appliances, according to different oral hygene maintenance programs. Material and method: We performed a randomized prospective study on 60 patients with fixed orthodontic appliances (17-25 years of age) devided in three study groups. The clnical indices recorded were: modified gingival index, plaque index and sulcular bleeding index. Statistical analysis or the results were carried out using Student $t$ test. Results: The patients were randomly divided into three groups: group A-patients were instructed to use electric brush, water flosser and interdental brush, group B- electric brush, interdental brush and fluoride and group C- manual brushing and fluoride. Statistical comparison of the values of the indexes with the Student $t$ test for independent samples showed statistically significant differences in all three groups of patients studied between initial and final values of all recorded clinical parameters. Conclusions: Fixed orthodontics do not induce periodontal disease if basic principles of oral hygiene are followed in compliant patients, which are correctly instructed to deal with real challenge, represented by complete elimination of debris and bacterial accumulation.
\end{abstract}

Keywords: orthodontic appliances, gingivitis, periodontal health.

Received: 12 November 2014 / Accepted: 1 December 2014

\section{Introduction}

Orthodontic treatment using fixed appliances represents a potential risk for periodontal health, as it increases the accumulation of oral biofilms and enhances inflammation of periodontal tissues. In these patients, periodontal maintenance programs must be carried out in conjunction to orthodontic treatment and also after completion of therapy [1-3].

Fixed appliances make brushing procedures more difficult and the patients are unable to completely remove dental plaque, which favors the development of gingivitis [4]. This is accompanied by the presence of gingival pockets and the subsequent bacterial colonization of subgingival areas, which may cause periodontal breakdown. According to data from scientific literature, removable appliances do not cause alterations of periodontal tissues, due to their easy maintenance measures [5-7].

The purpose of this study is to evaluate the clinical periodontal status by measuring specific indices during orthodontic treatment with fixed appliances after using different oral hygiene maintenance programs, in order to improve oral health status.

\section{Material and methods}

We performed a randomized prospective study on $60 \mathrm{pa}-$ tients between $17-25$ years of age ( 28 males and 32 females) under orthodontic treatment in the Clinic of orthodontics UMF Tirgu Mures between october 2012 and february

* Correspondence to: Tudor Hantoiu

E-mail: thantoiu@gmail.com
2014. The inclusion criteria were: patients with good general health, over 16 years of age, non smokers, with mild gingivitis - modified gingival index $(\mathrm{MGI})=1.5$ and plaque index (PI) Quigley-Hein modified by Turesky $=1.75$. We used the following exclusion criteria: teeth with extensive restorations, significant alterations of oral mucosa (others than gingivitis), adverse reactions to oral hygiene products, administration of antiinflammatory or antibiotic drugs 1 month prior to this investigation, regular use of antibacterial oral products two weeks before this study. The patients were randomly divided into three groups: group A-patients were instructed to use electric brush, water flosser and interdental brush, group B- electric brush, interdental brush and fluoride and group C- manual brushing and fluoride. During the first visit we recorded all the clinical parameters and then the patients were instructed to use different hygiene procedures for 14 days. All patients received scaling and proffesional cleaning. The second visit was schedueled after 14 days and the measurements were repeated. Each author evaluated the same index in each patient before and at the end of the investigation.

Modified Gingival Index (MGI). This index is used in clinical studies, it eliminates the use of periodontal probe and permits a noninvasive and reproductibile examination. Marginal gingiva was evaluated in four points for each tooth (disto-vestibular, vestibular, mesio-lingual and lingual). MGI for a patient was obtained by deviding the total number to the number of teeth examined.

Sulcular Bleeding Index (SBI). The purpose of this index is to identify gingival inflammation in early stages. A periodontal probe was inserted $1 \mathrm{~mm}$ in the gingival sul- 
cus paralell with the long axix of the tooth and moved in a mesio-distal direction. After 30 second the tendency to bleeding was evaluated, giving scores in 4 areas: disto-vestibular, vestibular, lingual and mesio-lingual. The mean SBI was obtained by deviding the total to the number of teeth examined.

Quigley-Hein Plaque Index (PI) modified by Turesky. It was used to evaluate the oral hygiene. Vestibular and lingual dental surfaces were devided in 3 areas and coloured with eritrosine. The amount of bacterial biofilm was then recorded based on visual inspection.

Statistical analysis of the results. The values obtained for MGI, SBI and PI were introduced in a data base and evaluated using statistic methods. For statistical comparison of clinical parameters in the same group before and after treatment Student $\mathrm{t}$ test was used. For the evaluation of mean values differences $\Delta \mathrm{MGI}, \Delta \mathrm{SBI}, \Delta \mathrm{PI}$ and determination of confidence interval and standard deviation we applied $\mathrm{t}$ test for pairred samples.

\section{Results}

Distribution of demographic characteristics and mean values of clinical parameters recorded durin the firs visit are presented in Table I.

The mean values of MGI diminished in group A from $1.73 \pm 0.31$ to $0.62 \pm 0.10$ at the final measurement. The same tendency was noted for group B where the mean value was reduced from $1.71 \pm 0.31$ to $0.64 \pm 0.19$. In group $C$ the variation was between $1.78 \pm 0.20$ to $1.41 \pm 0.19$ (Figure 1).

Statistical comparison using Student t test applied to the mean values of MGI at the first and second visit we found significant differences among groups $\mathrm{A}$ and $\mathrm{B}$. In the same time, in group $C$ the variation of MGI over the investigation period shows a significant decrease. $\mathrm{P}$ values are shown in Table II.
Table I. Demographic characteristics and mean values of clinical indices in the study groups at the first visit.

\begin{tabular}{|c|c|c|c|}
\hline $\begin{array}{l}\text { Clinical parameter } \\
\text { Initial / Final }\end{array}$ & $\begin{array}{c}\text { Group A } \\
\mathrm{N}=21\end{array}$ & $\underset{N=19}{\text { Group } B}$ & $\underset{N=20}{\text { Group C }}$ \\
\hline Age interval & $17-24$ & $18-25$ & $17-23$ \\
\hline Gender Male & 12 & 8 & 9 \\
\hline Female & 9 & 11 & 11 \\
\hline Mean value & $1.73 / 0,62$ & $1.71 / 0,64$ & $1.78 / 1,41$ \\
\hline Mean value & $0.62 / 0,24$ & $0.65 / 0,21$ & $0.63 / 0,58$ \\
\hline Mean value & $2.46 / 1,62$ & $2.63 / 1,81$ & $2.60 / 2,18$ \\
\hline
\end{tabular}

Table II. $p$ values for independent variables determined through the study period

\begin{tabular}{cccc}
\hline Compared values & Group A & Group B & Group C \\
\hline MG I initial compared to MGI final & $\mathrm{p}<0.05$ & $\mathrm{p}<0.05$ & $\mathrm{p}<0.05$ \\
SBI initial comparat to SBI final & $\mathrm{p}<0.05$ & $\mathrm{p}<0.05$ & $\mathrm{p}>0.05$ \\
PI initial compared to PI final & $\mathrm{p}<0.05$ & $\mathrm{p}<0.05$ & $\mathrm{p}<0.05$ \\
\hline
\end{tabular}

SBI in group A decreases from $0.62 \pm 0.12$ to $0.24 \pm 0.10$. In group $B$ there was a reduction in SBI mean value from $0.65 \pm 0.23$ to $0.21 \pm 0.14$; in group $C$ the variation was between $0.63 \pm 0.20$ to $0.58 \pm 0.16$ (Figure 2). Statistical comparison of SBI values at the first and second visit revealed a significant decrease for goups $\mathrm{A}$ and $\mathrm{B}$, while for group C there was not a statistically significant difference between the examinations (Table II).

Regarding the PI, for group A there is an important decrease over the study period, from $2.46 \pm 0.42$ to $1.62 \pm 0.30$, in group B we noted the same tendency, with a reduction from $2.63 \pm 0.42$ to $1.81 \pm 0.40$, while in group $C$ the values were $2.60 \pm 0.15$ in the first visit and $2.18 \pm 0.14$ in the second one (Figure 3 ).

Statistical comparison of these values with the Student $t$ test for independent samples showed statistically significant differences in all three groups of patients studied between initial and final values of all recorded clinical parameters (Table II).
Lot A

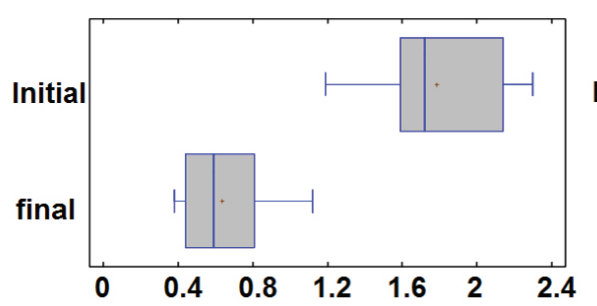

Lot B

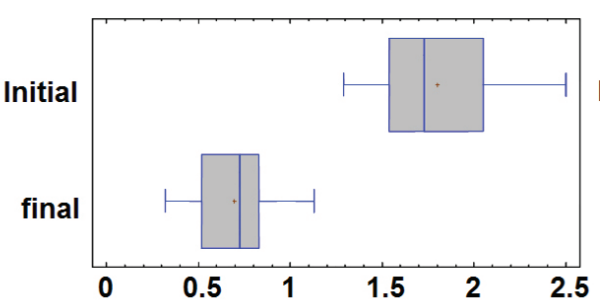

Lot C

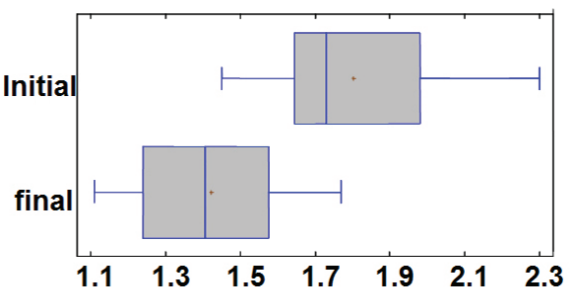

Fig. $1 \mathrm{MGl}$ initial and final mean values for the study groups.

group A

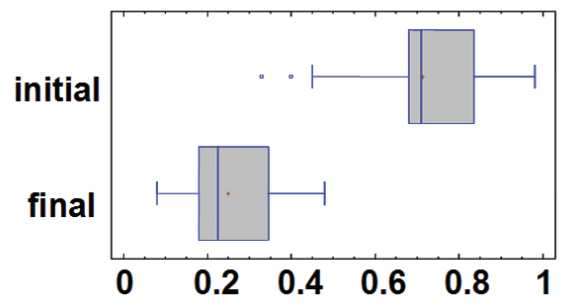

group B

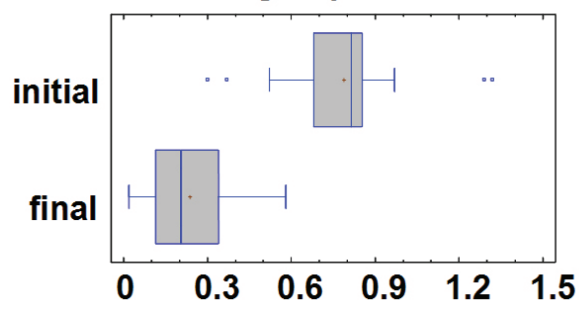

Group C

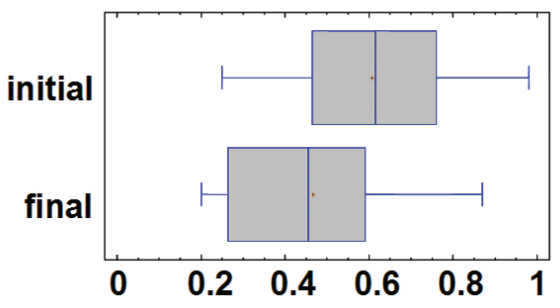

Fig. 2 Variation of SBI initial and final recordings at the first and second visit for the three study groups. 

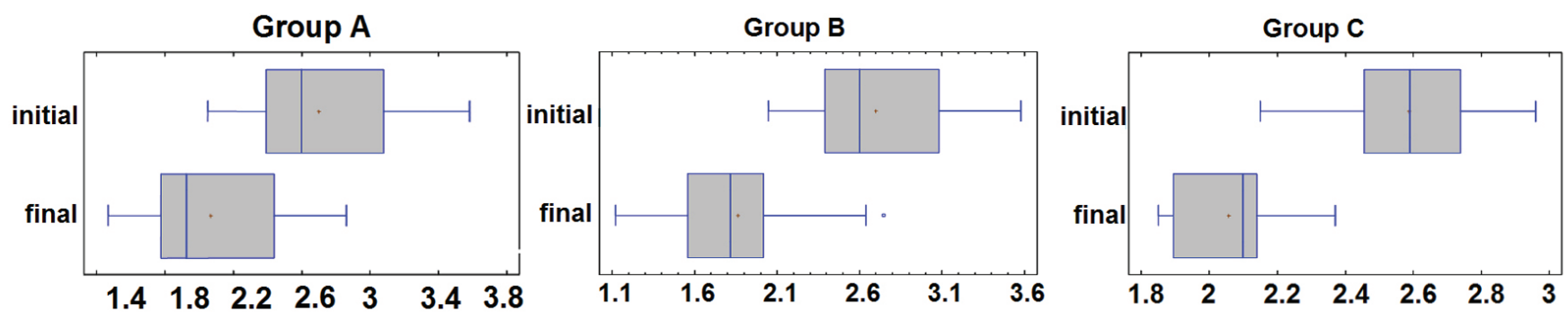

Fig. 3 Variations of PI values between the first and second visits for the three study groups.

\section{Discusion}

The diagnosis of gingivitis induced by bacterial dental plaque was based on clinical signs and MGI values: oral biofilm visible at the gingival margin, colour change and alterations variation of gingival contour, edema, loss of attachment or bone resorption. The evaluation of population sample shows no age related statistical differences between study groups $(\mathrm{p}=0.05)$ and comparison of MGI, SBI and PI values recorded for the study groups during the first visit shows also no statistical significance $(\mathrm{p}=0.05)$, which certifies the correct distribution of patients in the study groups.

MGI had an important reduction in groups A and B and less in group $\mathrm{C}$, but there was an important difference inside each group between the initial and final measurements. The decrease of MGI in group C patients is the result of scaling and professional cleanings performed the first treatment session. Mechanical removal of the main etiological factor entails an improvement of gingival status still present two weeks after professional cleaning.

Other studies showed the same tendency regardin MGI, which can be explained in part by Hawthorne effect, meaning that patients included in a clinical trial give more attention to oral health and dental hygiene measures [8-12].

There was a great decreasing tendency of SBI between the first and second visit for the patients of groups $\mathrm{A}$ and $\mathrm{B}$ with a statistical significant difference; in group $\mathrm{C}$ the difference was lesser and had no statistical significance. This shows that professional cleaning has little effect in reducing gingival bleeding after 14 days, when we noticed the return of SBI towards initial values, as there was no statistical differences between the initial and final measurements. SBI allows the diagnosis of early gingival inflammation (bleeding) when other clinical signs are not present $[13,14]$. These results are similar with other data, showing the tendency of the bleeding indexes to return to their initial values, two weeks after the initial sanitisation [15].

As for PI, it showed a decreasing evolution in all study groups between examinations, with a statistical significant difference. Same results were published in other studies, showing that the decrease of PI after professional cleaning is maintained over more than two weeks $[16,17]$. Our investigation showed that the best oral health maintainence programm is represented by the use of an electric brush, associated with water flosser and interdental brush, twice a day. Treatment of orthodontic patients must follow an interdisciplinary approach. All modalities of oral hygiene procedures and their effect on the periodontal tissues must be explained to the patient prior to fixed orthodontic treatment.

\section{Conclusions}

The presence of fixed orthodontic appliances makes the use of oral hygiene methods more difficult and prevents the complete mechanical removal of dental plaque, which increases the risk of detrimental consequences on soft dental tissues.

Accumulation of supra- and sub-gingival biofilms induces a pro-inflammatory state that can be followed by destructive periodontal reactions. The best oral hygiene method implies the use of powered dental brushes associated with interdental brushes and water devices.

Fixed orthodontics do not induce periodontal disease if basic principles of oral hygiene are followed in compliant patients, which are correctly instructed to deal with real challenge, represented by complete elimination of debris and bacterial accumulation.

\section{References}

1. Sanganash FG, Siddharth R, Sachin S: Periodontal Maintenance program in Orthodontic Patients. International J of Scientific Study, 2013,1(2):6571.

2. Boyd RL: Periodontal implications of orthodontic treatment in adults with reduced or normal periodontal tissues versus those of adolescents. Am J Orthod Dento-facial Orthop, 1989,96:191-199.

3. Boyd RL, Rose CM: Effect of rotary electric tooth brush versus manual tooth brush on decalcification during orthodontic treatment. Am J Orthod Dento-facial Orthop, 1994,105:450-456.

4. Putt M. Milleman J, Delaurenti M, Jenkins W, Wei J, Strate I. Comparison of plaque removal in orthodontics subjects by sonicare FlexCare and a manual brush. J Dent Res 87 (spec issue 8), 2008,2044-2050.

5. Sharma NC, Lyle DM, Qaquish JG, galustians J, Schuller R. Effect of a dental water jet with orthodontic tip on plaque and bleeding in adolescent patients with fixed orthodontic appliances. Am J of Orthod. \& Dentofacial Orthopedics, 2008, 133(4):565-571.

6. Chapman JA, Roberts WE, Eckert GJ, Kula KS. Risk factors for incidence and severity of whith spots lesions during treatment with fixed orthodontic appliances. Am J of Orthod \& Dentofacial Orthopedics, 2010,138: 188194.

7. Yun-Wah Lau P, Wing-Kit Wong R. Risks and complications in orthodontic treatment. Hong Kong Dental J, 2006;3:15-22.

8. Richter AE, Arruda AO, Peters MC, Sohn W. Incidence of caries lesions among patients treated with comprehensive orthodontics. Am J of Orthodontics \& dentofacial Orthopedics. 2011,139,:657-664.

9. A, Cunha-Cruz J, Bakko DW, Huang GJ, Hujoel P. The effects of orthodontic therapy on periodontal health. A systematic review of controlled evidence. JADA 2008,139;413-422.

10. Tefekci E, Dixon JS, Gunsolley JC, Lindauer SJ. Prevalence of white spot lesions during orthodontic treatment with fixed appliances. Angle Orthod, 
2011,81:206-210.

11. Van der Weijden F, Slot DE. Oral hygiene in the prevention of periodontal disease: the evidence. Periodontology 2000. 2011,55:104-123.

12. Claydon NC. Current concepts in tooth brushing and interdental cleaning. Periodontology 2000, 2008;48:10-12.

13. Kaklamanos EG, Kalfos E. Meta-analysis on the effectiveness of powered tooth brushes for orthodontic patients. Am J Orthod Dentofacial Orthop. 2008,133;187: 1-14.

14. Berchier CE, Slot DE, Haps S, van der Weijden GA. The efficacy of dental floss in addition to a tooth brush and plaque parameters of gingival inflammation: a systematic review. Int J Dental Hyg, 2008;6:265-279.

15. Goyal CR, Lyle DM, Quaquis JG, Schuller R. The addition of a water flosser to power tooth brushing: effect on bleeding, gingivitis and plaque. J Clin Dent. 2012;23:57-63.

16. NAM, Honnequin - Hoenderdos NL, Berchier CD, Slot DC, Lyle DM, van der Weijden GA. The effect of differeni interdental cleaning devices on gingival bleeding. J Int Acad Periodontol, 2011;13: 2-10.

17. Goyal CR, Lyle DM, Quaquish JG, Schuller R. Evaluation of the plaque removal efficacy of a water flosser compared to string floss in adults after a single use. J Clin Dent 2013,24:37-42. 